\title{
The Role of Fertility in the Demography of Grandparenthood: Evidence from Italy
}

\author{
Giorgio Di Gessa ${ }^{1}$ (1) $\cdot$ Valeria Bordone ${ }^{2}$ (1) $\cdot$ Bruno Arpino $^{3}$
}

Received: 19 February 2020 / Accepted: 28 September 2020/Published online: 14 October 2020

(C) The Author(s) 2020

\begin{abstract}
Grandparents play an important role in their family's lives. However, little is known about the demography of grandparenthood. Given dramatic recent changes in fertility, we explore the role of number of children and age at first birth in the timing of the transition into grandparenthood focusing on Italy, a country with well-known North-South fertility differentials. We used data from the 2009 Italian Survey 'Family and Social Relations' $(N=$ $10,186)$ to estimate median ages of grandparenthood across three birth cohorts of parents (1920-29; 1930-39; 1940-49). Findings show an overall postponement of age of grandparenthood of 5 years, shifting for women from early to mid- or late-50s (in the South and North, respectively). Such postponement is largely driven by family compositional changes: although the age of grandparenthood among mothers of three or more children has not changed much over cohorts, the percentage of mothers with such characteristic decreased significantly. The heterogeneity in experiencing the transition to grandparenthood has implications for intergenerational transfers and other roles in later life.
\end{abstract}

Keywords Transition to grandparenthood · Fertility profile $\cdot$ Median age at grandparenthood $\cdot$ Number of children $\cdot$ Age at first birth $\cdot$ Becoming a grandparent

\section{Introduction}

Researchers have become increasingly interested in grandparents as populations age and the economic and social roles of grandparents in society and family life have

Electronic supplementary material The online version of this article (https://doi.org/10.1007/s12062-02009310-6) contains supplementary material, which is available to authorized users.

Giorgio Di Gessa

g.di-gessa@ucl.ac.uk

1 Research Department of Epidemiology and Public Health, University College London, 1-19 Torrington Place, London WC1E 7HB, UK

2 Department of Sociology, University of Vienna, Vienna, Austria

3 Department of Statistics, Computer Science, Applications, University of Florence, Florence, Italy 
become more visible (Bengtson 2001). In particular, grandparents play an important role in providing informal childcare to families. In Europe, 58\% of grandmothers and $49 \%$ of grandfathers look after at least one of their grandchildren under the age of 16 (Hank and Buber 2009). Therefore, numerous studies have investigated the impact of grandchild care provision on younger generations' fertility (Aassve et al. 2012; Pink 2018), on mothers' (Arpino et al. 2014) and grandmothers' labour force participation (Di Gessa et al. 2016; Lumsdaine and Vermeer 2015; Zanasi et al. 2019) as well as on grandparents' health and well-being (Arpino and Bordone 2014; Chen and Liu 2012; Di Gessa et al. 2016a, 2016b; Hank et al. 2018; Tsai et al. 2013).

Yet, we still know little about the timing of the transition to grandparenthood. In this study, we investigate fertility differences in the transition to grandparenthood, filling gaps in the knowledge about one of the most common transitions in later life. It is quite straightforward that how many people become grandparents and at what age depend mostly on demographic trends, namely longevity, their own and their children's fertility quantum and timing. For instance, increased life expectancy means it is now quite common for a child to grow up while their grandparents and even great-grandparents are alive (Hagestad 2006; Murphy 2011). While shifts in fertility -including childlessness - affect both the percentage of the population that ever becomes grandparent and the timing of this transition. If age at first birth for two successive generations (G1 and G2) were identical, the expected age of grandparenthood for G1 would be about double their age of parenthood. However, with the advent of the so-called second demographic transition (Lesthaeghe 2010), most European countries have witnessed a steady rise in childlessness, an upward trend in age at first birth, and declining parity distribution across the cohorts born after the Second World War. Whereas European women born between 1945 and 1949 reached the lowest levels of permanent childlessness at 8-10\%, childlessness has doubled (around 16\% to 20\%) among women born 20 years later (Miettinen et al. 2015; Sobotka 2017). Similarly, in most European countries, the mean age at first birth (MAFB) has increased substantially for the cohorts born after 1960 (Frejka and Sardon 2006). Overall, declines in fertility coupled with increased timing of parenthood suggest a delay in the timing of grandparenthood.

So far, only a few studies have investigated the timing of grandparenthood and how this has changed across cohorts. Leopold and Skopek (2015a), using data from the USA and Europe, compared the median age of grandparenthood among those born roughly between 1930 and 1947 demonstrating considerable heterogeneity across countries. The same authors, comparing the median age of grandparenthood among East and West German women born 1929-1958 (Leopold and Skopek 2015b), found that women born 1949-1958 had an estimated median age of grandparenthood between 5 (West) and 6 (East) years higher than those born 20 years earlier (i.e. between 1929 and 1938). Using Canadian data, Margolis (2016) also found a substantial delay of grandparenthood over time: 58\% of women aged 50-54 were grandmothers in 1985 compared to only $29 \%$ in the same age group in 2011 , with an increase in median age of grandmotherhood of about 10 years in a quarter of a century. More recently, employing simulation techniques, Margolis and Verdery (2019) found that the median age of grandparenthood in the USA increased from the mid-40s among women born in the 1880 s to the late -40 s among those born in the 1960 s, with a convergence in age for black and white women. Thus, this literature suggests that the prevalence and timing of the transition to grandparenthood are undergoing rapid change in response to global 
trends of declining fertility. However, none of these studies explicitly examined the role that changes in fertility had on the transition into grandparenthood, and its timing, across and within cohorts. An exception is the paper by Skopek and Leopold (2017) which attempted to show such differences using educational gradients as a proxy for different fertility histories.

Our paper adds to the existing knowledge on the demography of grandparenthood by exploring directly the link between fertility profiles (i.e., number of children and age at first childbirth) and the transition to grandparenthood. In this respect, we aim to shed light on between- and within-cohort differences. We therefore explore the likelihood of grandparenthood at various age-thresholds and the median age of grandparenthood by number of children and age at first birth over three decades. We do so with relation to the Italian context. Given that Italy is well-known for its North-South differential in fertility profiles (see section below), it provides a lens through which to explore -within the same country - how different fertility profiles affect the age at transition to grandparenthood between and within cohorts. Moreover, grandparents in Italy play an important role as providers of childcare, with $43 \%$ of grandchildren aged 0-13 cared for by grandparents occasionally and about $20 \%$ looked after by them almost daily when their parents are at work (Zamberletti et al. 2018). The availability of such informal childcare is key to the Italian maternal labour force participation, particularly among the most socio-economically disadvantaged mothers (Arpino et al. 2014).

\section{Italy as a 'case study': North-South fertility differences between and within cohorts}

Italy is an informative country to study the effect of fertility profiles on the transition to grandparenthood over time. It is well-known that the North and the South of Italy have witnessed marked differentials in their fertility levels and their demographic shifts over time (Caltabiano 2016; Dalla Zuanna and Micheli 2004). Comparing the North and the South of Italy, therefore, offers the opportunity to explore the overall effect that changes in fertility rates (and in family size) and MAFB have had both across and within cohorts on the timing of the transition to grandparenthood.

Currently, about two thirds of the Italian population live in the North; the North has a slightly higher life expectancy at birth (83.3) than the South (82.3) and an older population (the average age in the North is 46 whereas in the South is 44.3) [see dati. istat.it]. Although these two geographical areas differ (and have differed over time) by a number of socio-economic and demographic indicators (Salvini and De Rose 2011; Santarelli 2011), given the scope of our research, we focus on two main North-South fertility differences. First, although the cohort fertility rate (CFR) in Italy has declined throughout the twentieth century, Southern Italian CFR has been consistently higher than in the rest of the country, with a value of 3.3 for the 1920 birth cohort and almost 1.9 for women born in 1965, compared to about 2.1 and 1.4, respectively, in the North (see Fig. 1).

Unsurprisingly, childlessness rates and family sizes have developed differently in the North and South of Italy. For instance, whereas among the oldest cohorts childlessness was more common in the South of Italy, from the 1960s it has been more prevalent in the North (Tanturri and Mencarini 2004). Also, as shown in Fig. 2, the percentage of women with only one child increased in the North from already about a quarter to almost a third among women born in 1930 and 1950, respectively; whereas it 


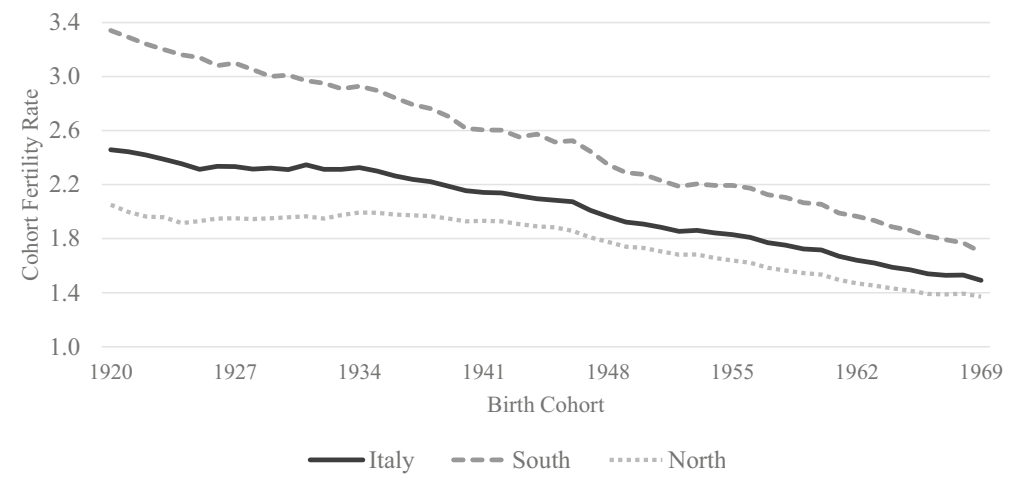

Sources: Own elaboration of data from ISTAT $(1997,2017)$.

Fig. 1 Cohort fertility rate in Italy and by geographical areas (cohorts born 1920-1969)

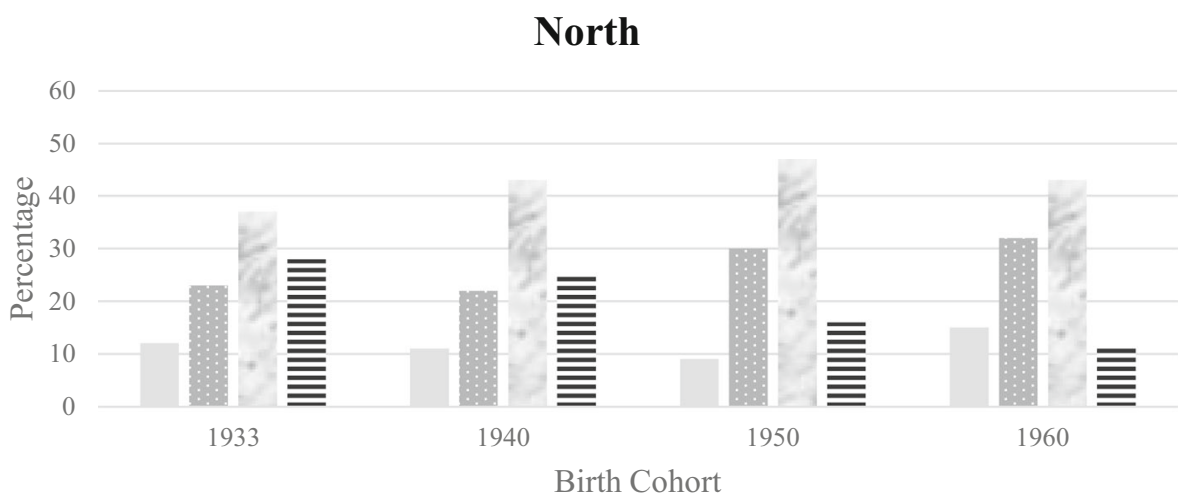

\section{South}

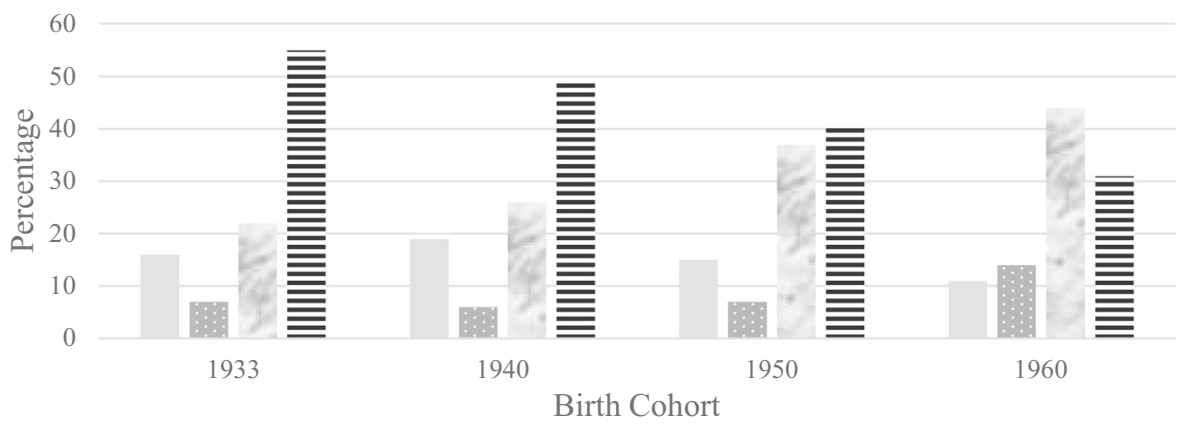

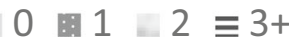

Source: Own elaboration of data from ISTAT (2017)

Fig. 2 Percentage of women who have completed their childbearing with $0,1,2,3+$ children, by birth cohort and geographical area (selected cohorts) 
remained stable at about $10 \%$ in the South. On the contrary, more than half of Southern Italian women born in 1930 had three or more children compared to a quarter in the North of Italy, and this difference remained remarkable also among those born in 1950 ( $41 \%$ of women in the South had 3 or more children compared to $16 \%$ in the North) (Rosina 2004).

Second, women's MAFB has increased differently in the North and the South, particularly among women born from the mid-1950s. Overall, Italian women born between 1930 and 1955 experienced a decline in MAFB (from about 26 to 24.8) with little variation across geographical areas (see Fig. 3 for more details). However, since the 1955 birth cohort, the MAFB has increased faster in the North: the North-South gap in MAFB raised from 0.84 for the 1955 birth cohort to almost 2.6 years for the cohort of women born in 1969 .

Considering the timing of grandparenthood, these demographic changes suggest that one should expect, overall, a later entry into grandparenthood over cohorts, with earlier transitions among Southern Italians who tended to have more children at younger ages.

\section{Data and Methods}

We used data from the latest available Survey on 'Family and Social Relations' ('Famiglia, soggetti sociali e condizione dell'infanzia'), collected in 2009. This is a nationally representative study which collects information on a range of contemporaneous and retrospective demographic and socio-economic characteristics for about 44,000 individuals aged 18 and older who reside in Italy (ISTAT 2009).

All respondents were asked whether they were grandparents at the time of interview, and if so, how many grandchildren they had. Grandparents were also asked the age of up to three grandchildren. Those who had 4 or more grandchildren were asked to refer to the three living geographically closest to them. To determine the timing of grandparenthood (i.e., the age at transition into grandparenthood), we calculated the respondent's age at the time of the oldest grandchild's birth. For respondents with up to three grandchildren ( $64 \%$ of grandparents in the sample), this was simply calculated by subtracting the age of the oldest grandchild from the age of the respondent. For those

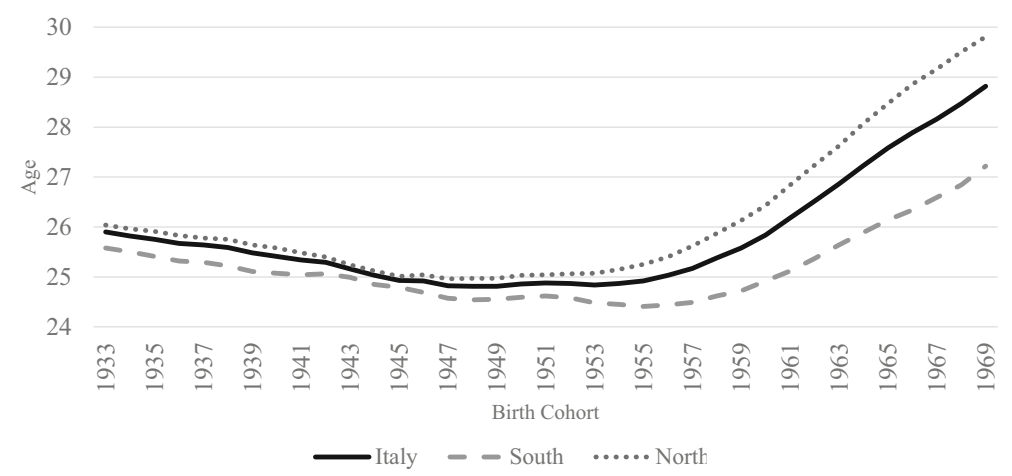

Source: Own elaboration of data from ISTAT (2017).

Fig. 3 Mother's average age at first childbirth in Italy and by geographical areas (cohorts born 1933-1969) 
with four or more grandchildren (36\% of grandparents in the sample), we considered the lowest age between (i) the age calculated by subtracting the age of the oldest grandchild among the three reported from the age of the respondent and (ii) the youngest age at which any of the respondent's children left home. ${ }^{1}$ In this latter case, we added 2 years assuming that respondents would become grandparents in about 2 years' time from when their child left the parental home.

This is a reasonable assumption for the cohorts under study for two main reasons. First, several studies have shown a strong correlation between residential autonomy and marital/fertility behaviours, particularly in Italy and among older cohorts. Indeed, almost $90 \%$ of Italians born in the 1950s and mid-1960s (i.e., approximately the children of the birth cohorts considered here) left their parents' home to get married, with little difference between the North and South of Italy. For those birth cohorts, transition to parenthood was also likely within the first year of marriage (Billari and Kohler 2000; Billari et al. 2001; Rosina and Fraboni 2004). Second, our data show that among respondents with up to three grandchildren (i.e., those for whom we can establish the exact age of grandparenthood), there is a strong correlation $(r=0.67)$ between the ages of grandparenthood calculated with the two methods described above.

Overall, we replaced the exact age of grandparenthood with the youngest age at which any of the respondent's children left home (plus 2 years) only for about $14 \%$ of all grandparents in the sample. As robustness check, we carried out the same analyses only on the sample for which the exact age of grandparenthood was available, and these yielded similar trends (see Supplementary material).

\section{Analytical Sample and Main Variables of Interest}

From the original sample $(N=43,850)$, we selected respondents aged 60 and over at the time of the interview with at least one child, obtaining a working sample of 5623 mothers and 4563 fathers $(N=10,186)$ who could be "at risk" of grandparenthood. We decided to focus on respondents aged 60 and over as for the younger cohorts we could not calculate their median age of grandparenthood. For example, only about $20 \%$ of respondents born in the 1950 s (that is 50-59 years old at interview) had become grandparents by the time of the interview.

Based on a question on residency at the time of the interview, we stratified the sample by geographical area (North and Centre, hereafter referred to as the North, and South, based on the statistical partition proposed by ISTAT) and birth cohort (1920s, 1930s, and 1940s). Respondents were asked a number of questions about their fertility histories, based on which we distinguished between respondents with one, two, and three or more children. Following Keenan and Grundy (2018), we then considered age of parenthood by including a trichotomous variable, indicating whether the respondent became a parent before the age of 21 , between 22 and 29 , or at 30 or older.

\footnotetext{
${ }^{1}$ This information is available for up to seven children (i.e., $99.6 \%$ of all the sample).
} 


\section{Methodological Approach}

After presenting descriptive statistics, we use survival analysis (Blossfeld et al. 2007) to examine the age at transition to grandparenthood. Following Leopold and Skopek (2015b), we set the time axis to start in a respondent's year of birth and to end at the age at which the first grandchild was born. If no grandchild was born, we censored the process at the interview date. Using Kaplan-Meier estimates, we first calculated the median age of grandparenthood and then the probabilities of being a grandparent at different selected ages (that is at 45, 50, 55, 60, and 65). This way we can show how timing and likelihood of grandparenthood differ across and within cohorts by fertility profiles and in a comparative perspective across North and South.

All analyses are implemented separately for men and women, as previous studies have reported different ages of grandmotherhood and grandfatherhood, in line with age differences in the timing of first marriage by gender (Leopold and Skopek 2015a, 2015b; Margolis 2016). However, given that the main results and trends are similar, we present results only for women and comment on those for men (available online as Supplementary material). For all analyses and descriptive tables we used weights, based on the population's marginal distribution coefficients provided by ISTAT.

\section{Results}

\section{Descriptives}

In 2009 (the year of interview), 72\% of fathers and $81 \%$ of mothers aged 60 and over are grandparents in Italy. However, there is substantial variation across cohorts and geographical areas (Table 1). Over cohorts, we notice a decrease in the proportion of both mothers and fathers who have become grandparents by the age of 60, in the North as well as in the South. For instance, about $76 \%$ of Southern Italian mothers born in the 1920 s have become grandmothers by the age of 60 compared to $66 \%$ of those born two decades later.

As expected, Table 1 highlights not only between- but also within-cohort geographical variations. Indeed, the percentages of parents who turn grandparents are always lower in the North compared to the South, reflecting the lower fertility of younger generations in the North. For instance, about $72 \%$ of Northern mothers born in the 1920s have become grandmothers by the age of 60 compared to $56 \%$ of those born two decades later. Similarly, while the percentage of men and women with three children or more declined everywhere in Italy over the cohorts under study, larger families remain more common in the South than in the North. About $20 \%$ of Italian women born in the 1940s have three children or more in the North compared to $44 \%$ in the South. In the same cohort, one third of women have only one child in the North compared to $15 \%$ in the South.

\section{Timing of Grandparenthood}

Figure 4 (upper panel) presents the estimated median age (i.e., the 50th percentile) at grandparenthood for mothers of the three cohorts and two geographical areas under 
Table 1 Descriptive statistics (\%) on the total sample and on the parents' sample, by gender, geographical area, and cohort

\begin{tabular}{|c|c|c|c|c|c|c|c|}
\hline & & North & & & South & & \\
\hline & & $1920 \mathrm{~s}$ & $1930 \mathrm{~s}$ & $1940 \mathrm{~s}$ & $1920 s$ & & $1940 \mathrm{~s}$ \\
\hline & & $\%$ & $\%$ & $\%$ & $\%$ & $\%$ & $\%$ \\
\hline W O M E N & & & & & & & \\
\hline ALL SAMPLE $(N=$ & 6496) & & & & & & \\
\hline Childless & & 16.3 & 11.9 & 11.0 & 14.9 & 14.6 & 12.5 \\
\hline Grandparent & & 72.6 & 73.4 & 56.0 & 79.6 & 77.2 & 65.9 \\
\hline $\mathrm{N}$ & & 873 & 1493 & 1651 & 546 & 918 & 1015 \\
\hline MOTHERS $(N=562$ & 23) & & & & & & \\
\hline Number of children: & 1 & 33.1 & 26.4 & 31.0 & 18.2 & 12.1 & 15.2 \\
\hline & 2 & 40.3 & 44.5 & 49.8 & 27.6 & 34.5 & 40.8 \\
\hline & $3+$ & 26.6 & 29.1 & 19.2 & 54.2 & 53.4 & 44.0 \\
\hline Age of parenthood: & $\leq 21$ & 17.9 & 14.2 & 17.6 & 14.9 & 21.1 & 24.0 \\
\hline & 30 & 21.8 & 17.9 & 15.2 & 26.5 & 21.1 & 18.3 \\
\hline Mean (years) & & 26.1 & 26.0 & 25.3 & 26.7 & 25.8 & 25.3 \\
\hline Grandparent & & 88.7 & 85.2 & 66.3 & 93.9 & 90.0 & 72.8 \\
\hline Grandparent by age 6 & & 71.8 & 66.6 & 56.2 & 75.9 & 74.2 & 65.5 \\
\hline $\mathrm{N}$ & & 732 & 1301 & 1468 & 463 & 781 & 878 \\
\hline M E N & & & & & & & \\
\hline ALL SAMPLE $(N=$ & 5213) & & & & & & \\
\hline Childless & & 11.0 & 12.2 & 13.7 & 8.3 & 9.8 & 9.4 \\
\hline Grandparent & & 79.3 & 69.0 & 45.2 & 83.8 & 78.7 & 54.9 \\
\hline $\mathrm{N}$ & & 470 & 1199 & 1544 & 334 & 715 & 951 \\
\hline FATHERS $(N=4563$ & & & & & & & \\
\hline Number of children: & 1 & 27.7 & 26.6 & 34.4 & 14.8 & 13.2 & 11.8 \\
\hline & 2 & 43.8 & 48.6 & 50.0 & 32.9 & 38.3 & 47.4 \\
\hline & $3+$ & 28.5 & 24.8 & 15.6 & 52.3 & 47.5 & 40.8 \\
\hline Age of parenthood: & $\leq 21$ & 3.0 & 2.3 & 2.9 & 3.8 & 5.2 & 4.9 \\
\hline & 30 & 54.7 & 44.9 & 35.4 & 53.1 & 45.8 & 40.8 \\
\hline Mean (year) & & 30.4 & 29.7 & 29.1 & 30.6 & 29.6 & 29.3 \\
\hline Grandparent & & 89.1 & 78.7 & 52.6 & 91.3 & 87.1 & 60.6 \\
\hline Grandparent by age 6 & & 55.1 & 46.7 & 39.6 & 62.9 & 62.9 & 50.3 \\
\hline $\mathrm{N}$ & & 415 & 1041 & 1315 & 301 & 636 & 855 \\
\hline
\end{tabular}

Source: Own calculations on data from Famiglia, soggetti sociali e condizione dell'infanzia (2009)

Note: Parents' samples are subsamples of the total sample. Weighted data

study, from survival analysis. Mothers in the North of Italy (an area characterised by smaller families and by postponement of childbearing in more recent decades) become grandmothers between 2 and 4 years later than those in the South. Moreover, while overall the age of grandmotherhood increases significantly over cohorts, the rise is of 
5 years in the North (from 53 among women born in the 1920s to 58 among those born in the 1940s) compared to 4 in the South (from 51 up to 55).

Additionally, we estimate timing of grandparenthood by number of children (Fig. 4, middle panel) and age at first birth (Fig. 4, bottom panel). Interestingly, increases in age of grandmotherhood over cohorts are bigger for mothers of an only child and those who had their first child after the age of 30 compared to those who had two or more children or whose first child was born before the age of 21 . For instance, mothers of three or more children face a postponement in the age of grandparenthood by about 2 to 3 years over cohorts in the two areas considered, while for mothers of an only child the mean age of grandmotherhood increases of 6 years in the North and of 9 years in the South between the 1920s and the 1940s birth cohorts (Fig. 4, middle panel). Similarly, the median age of grandmotherhood increases (non-statistically significantly) by 2-3 years over the birth cohorts considered for mothers whose first child was born before the age of 21 (remaining below the age of 50), while it increases by 8 years (approaching the mid- to late-60s) among those mothers who had their first child after their 30th birthday (Fig. 4, bottom panel).

Few significant within-cohort variations emerge across geographical areas when we consider specific fertility profiles. Indeed, when comparing the mean age of grandmotherhood between North and South for mothers within a specific fertility profile (i.e., 1, 2, or 3+ children) and within a specific birth cohort (i.e., 1920s, 1930s, or 1940s), Fig. 4 shows broadly similar ages at transition into grandparenthood. For instance, both mothers in the North and the South born in the 1940s who had their first child before the age of 21 became grandmothers at the age of 47 .

A more detailed picture of such differences and similarities can be seen in Table 2, which shows selected results of the Kaplan-Meier estimates for rates of grandmotherhood at different ages, and separately by fertility profiles. Below we comment on the two extreme categories of number of children (1 vs 3+) and of age of parenthood ( $\leq 21$ vs $30+)$.

Overall, regardless of the geographical area, between $79 \%$ and $89 \%$ of Italian mothers in the cohorts under study have become grandmothers by the age of 60 if they had three or more children, with higher percentages among the oldest cohorts (see Table 2, upper panel for full details). Among mothers with an only child, the percentage who experience this transition by age 60 is generally lower, but also shows a decline over cohorts both in the North and the South of Italy. For instance, 55\% (North) and 57\% (South) of women born in the 1920 s with an only child have become grandmothers by the age of 60 compared to less than $40 \%$ of those born two decades later.

When we consider age at first childbirth (Table 2, bottom panel), we find that women who became mothers at young ages $(\leq 21)$ are consistently more likely to become grandmothers earlier, both in the North and the South, and across time, with more than $80 \%$ of 'early' mothers transitioning into grandmotherhood by the age of 60 in all geographical areas and cohorts considered. The percentage of 'late' mothers who become grandmothers by age 60 decreases more rapidly over time, but figures in the North and South are not too dissimilar. For instance, $41 \%$ (North) and $46 \%$ (South) of women born in the 1920s who became mothers at 30 or older have become grandmothers by the age of 60 compared to $13 \%$ (North) and $21 \%$ (South) of those born two decades later. 

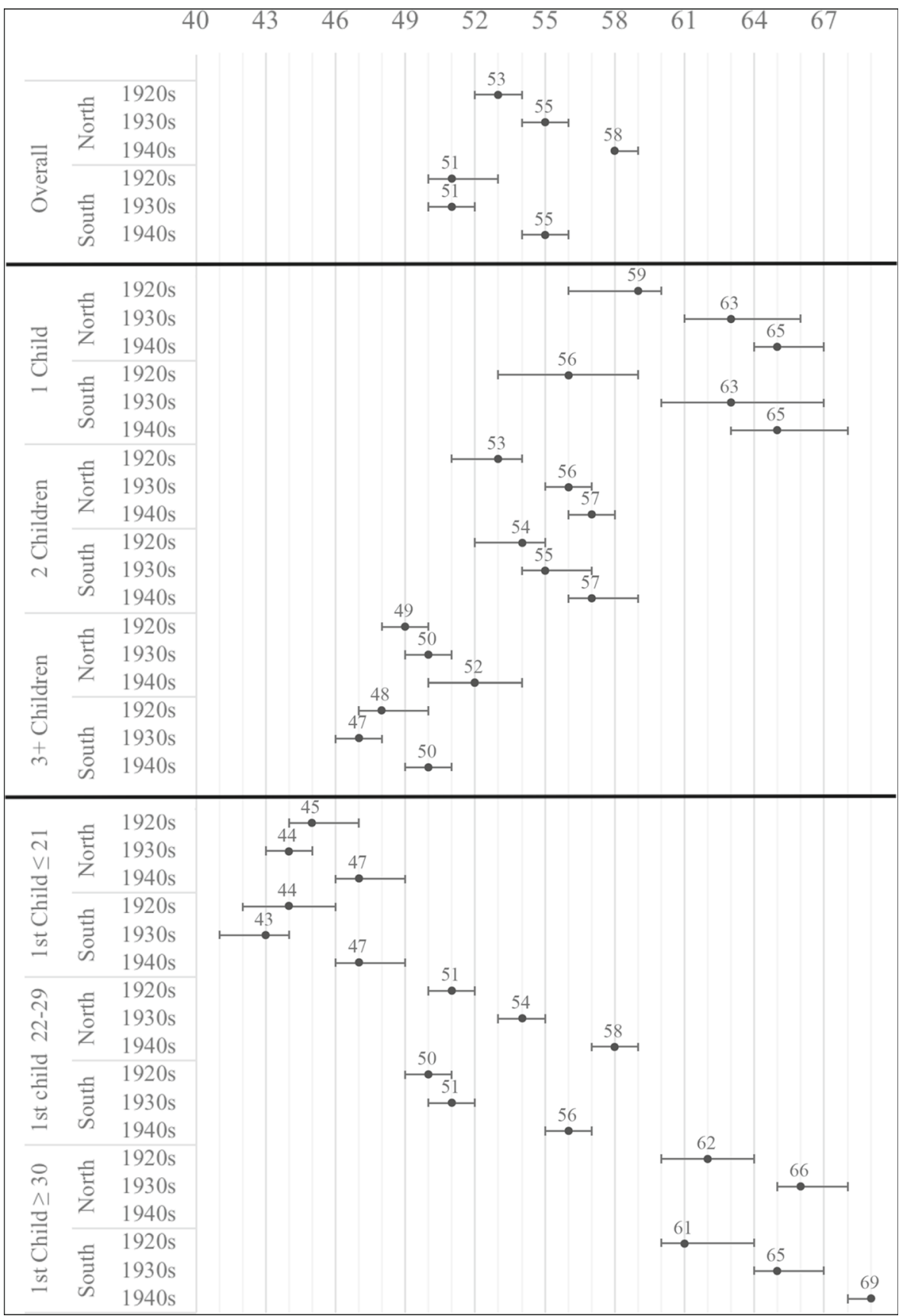

Source: Own elaboration of data from Famiglia, soggetti sociali e condizione dell'infanzia (2009). Notes: Analyses restricted to mothers. The graph shows median ages and 95\% confidence intervals based on KaplanMeier estimations. No data available for the 1940s Northern mothers whose first child was born after the age of 30 as less than $50 \%$ of this group had experienced grandmotherhood before the interview date.

Fig. 4 Median age of grandmotherhood by geographical area, cohort, and selected indicators of fertility 


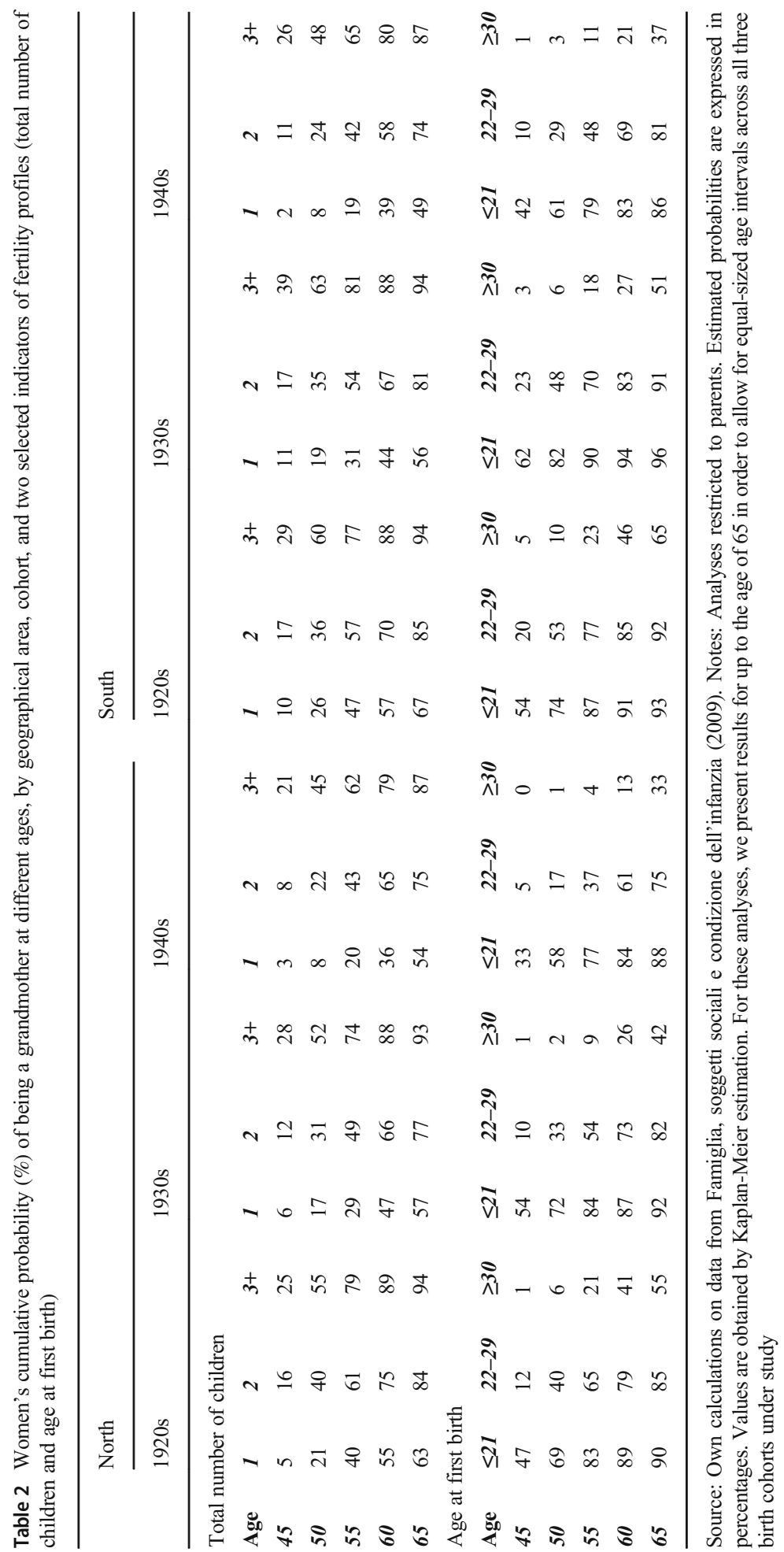


Results for fathers (available online as Supplementary material) yield similar conclusions, although the transition to grandparenthood occur, on average, about 5 years later for all cohorts and geographical areas considered, reflecting the usually older age of men in couples. Yet, increases in the median age at this transition are similar to those observed among mothers. From the 1920s to the 1940s birth cohorts, mean age of grandfatherhood rises from 59 to 63 in the North, and from 55 to 61 in the South. Also among fathers, regardless of the decade of birth and the area considered, those who had their first child above age 30 and those who had one child only transition into grandparenthood later (in the mid- to late-60s and beyond), particularly among the most recent cohorts under study.

\section{Discussion and Conclusions}

This study explicitly investigates the role of fertility in the transition to grandparenthood, filling gaps in the knowledge about one of the most common role transitions in later life. Using data from Italy and exploiting its well-known fertility differences over cohorts and across geographical areas, this study finds a postponement in the timing of grandparenthood across subsequent birth cohorts. Overall, our results show that both men and women born in the 1940s had an estimated median age of grandparenthood of about 5 years higher than those born in the 1920s, in line with what observed in Germany by Leopold and Skopek (2015b), shifting the transition to grandmotherhood from the early $50 \mathrm{~s}$ to the mid- (South) and late- (North) 50s. Additionally, our analyses suggest that increases in age of grandmotherhood over cohorts are bigger for mothers of an only child and those who had their first child after the age of 30. This is in line with studies which suggest that, although children's fertility behaviour might reflect their parents' fertility values and preferences, this intergenerational transmission of age at first birth is particularly pronounced at younger ages (Kim 2014), with more recent cohorts of children of older parents more likely to postpone entry into parenthood than children of younger parents (Steenhof and Liefbroer 2008). Also, those who grew up in a family with many siblings might have a preference for larger family and therefore have their first child earlier (Rijken and Liefbroer 2009). Finally, our paper provides some empirical evidence for the link between the shift of the transition to grandparenthood and fertility compositional changes across cohorts and geographical areas. Indeed, for instance, the median age of grandparenthood for mothers with fertility profiles characterised by three or more children has not changed much across cohorts and does not significantly differ between the North and the South of Italy, but the prevalence of this fertility profile has declined over time in both areas. Only 19\% of mothers born in the 1940s had large families in the North (down from 28\% for those born in the 1920s) compared to $44 \%$ in the South (down from $54 \%$ ).

Our findings have important implications for research on grandparenthood and related areas of study, such as grandchild care. The age when parents (eventually) become grandparents is a key factor not only for the experience of grandparenthood itself but also for its intersection with other life events, both 
grandparents' and (grand)children's. First, our analyses suggest that given current cohort trends in fertility (with increasing age at childbirth and levels of childlessness), subsequent cohorts of men and women are more likely not to experience the transition into grandparenthood at all and, if they do, to experience it at later ages. This may in turn affect the subjective perception of this event as well as the meaning, experience, expectations, and responsibilities attached to this role (Bordone and Arpino 2016; Hagestad and Lang 1986; Kaufman and Elder 2003). Such postponement is also coupled with fewer grandchildren which may affect how grandparents relate to their grandchildren, with more exclusive relations to them compared to the past (Hank et al. 2018).

Second, our results suggest that the overall postponement of median age of grandparenthood is not uniform across different subgroups of mothers and fathers, with those having large and early families experiencing this transition at younger ages than those with fewer and later born children. This is important because depending on the timing of the transition, the grandparent role may compete with other responsibilities, and roles (including labour force participation and caregiving to spouse and own parents just to name some) (Arpino and Bordone 2017; Arpino and Gómez-León 2019; Leopold and Skopek 2015a; Szinovacz 1998). Even in low fertility countries like Italy, a non-negligible percentage of women (about 15\%) born in 1970 still completed their fertility histories with three or more children (ISTAT 2017). These mothers are likely to become grandmothers at an age characterised by the prospect of juggling multiple roles, combining paid work with family-caring obligations (Evandrou and Glaser 2004; Vlachantoni et al. 2019). Supporting these women who might have to provide care for both their parents and their grandchildren while being in paid employment still remains a critical challenge. This is central and timely in both research and policy agendas given that becoming a grandparent increases early retirement and that grandchild care conflicts with both paid work and participation in social activities (Arpino and Bordone 2017; De Winter and Van Bavel 2013; Di Gessa et al. 2016; Zanasi et al. 2019).

Third, our findings have revealed how country averages may hide the differences between regions within a country. With the exception of Leopold and Skopek (2015b) who have shown how East and West German parents have shifted their transitions to grandparenthood at different ages, so far studies on the demography of grandparenthood have focused on between-country differences. However, many factors affecting fertility and grandparenthood operate at regional level (including socio-economic, institutional, and cultural factors), with considerable and historical differences in family practices and value patterns between regions within countries (Beugelsdijk et al. 2006; Duranton et al. 2009) which might even be bigger than differences between countries (Santarelli and Cottone 2009; Viazzo 2003). Allowing to account for such variations within countries instead of treating them as a uniform whole might help provide a more nuanced picture of complex societies. Previous studies on grandparenting have already shown how important it is to take the regional heterogeneity in family life into account when investigating the exchange of support between grandparents and grandchildren (Jappens and Van Bavel 2012; Phillips and Alexander-Eitzman 2016). Neglecting within-country differences when investigating also grandparenthood might provide a more opaque picture particularly where differences in family lives and fertility profiles are clearly present (Arpino and Tavares 2013; Campisi et al. 2020; Sigle 2008). 
Fourth, our results suggest that the changing profile of grandparenthood may also impact on the type and quality of intergenerational exchanges of time and monetary resources. For example, given that the health of grandparents has important implications for intergenerational transfers (Di Gessa et al. 2016; Hank and Buber 2009), those who become grandparents later might be less likely to provide care to their grandchildren in light of current trends in disability and functioning among older people (Chatterji et al. 2015; Margolis and Wright 2017).

A few limitations of our study should however be acknowledged. First, the most important limitation is that, as explained in the method section, our data did not allow us to calculate the exact age of grandparenthood for about a third of grandparents. Robustness checks (see Supplementary material) were carried out on the subgroup of respondents for whom we have the exact age of grandparenthood. These analyses tend to yield higher point estimates (overall by about 3 years) with wider confidence intervals (given that we consider fewer respondents). This is particularly the case in the South (where $50 \%$ of grandmothers have 4 or more grandchildren compared to $28 \%$ in the North), and among mothers who had their first child at younger ages and had 3 or more children. In the supplementary Table 2, the shift of about 3 years in the point estimates is mostly driven by the fact that the vast majority of grandmothers who have three grandchildren or fewer had one $(27 \%)$ or two children $(54 \%)$. Nonetheless, these additional analyses on the smaller sample of grandparents with the exact information on their transition to grandparenthood showed, similarly to the main analyses, that women born in the 1940 s became grandmothers about 5 years later than those born two decades earlier, shifting the transition to grandmotherhood from the mid-50s to the early-60s (61 in the North, and 60 in the South). They also show that such increases are bigger for mothers of an only child (although, in this case, this is true only for grandmothers in the South). Finally, even considering the exact age, median ages at transitions are similar by fertility profiles across cohorts and geographical areas. For instance, both in the North and in the South, mothers born in the 1940s with 3+ children became grandmothers at 57 , a similar median age of mothers with $3+$ children born two decades earlier.

Among other limitations, in our study we could not consider how current fertility changes are affecting the transition to grandparenthood for the most recent cohorts of people. Other studies (see Leopold and Skopek (2015b)) have extrapolated estimates for respondents who had not become grandparents by the time of the interview. However, such extrapolations rely on parametric assumptions which cannot be tested directly. Moreover, in our study, this would have implied imputing data for up to $80 \%$ of the most recent cohort (leading to debatable interpretations), given that only $20 \%$ of respondents born in the 1950s had become grandparents by the time of the interview (i.e. when they were aged 50-59). Furthermore, given our focus on age of grandparenthood, our study considered only respondents with children (i.e., "at risk" of grandparenthood). Only with more accurate data on the fertility of two successive generations, further studies will be able to shed light on how more recent changes in childlessness and timing of fertility of the second generation as well as how the number and sex composition of children affect both the likelihood of the transition into grandparenthood and its timing.

Moreover, it is important to acknowledge that selective attrition due to health and mortality could bias age distributions. Life expectancy in the first half of the twentieth 
century in the South of Italy was about 3 years lower than in the North, with the gap reducing and converging since the 1960s (Felice 2007). Also, evidence suggests that fertility history is associated with mortality in complex ways, with young mothers and those with one child or four or more children having higher mortality than other women (Barclay et al. 2016; Grundy and Tomassini 2005). The approach used in this paper is based on the rather strong assumption that mortality is not selective with respect to fertility whereas it is likely that our cohort estimates are subject to selection bias among mothers born in the oldest cohorts, those with one child (in the North), and those with 3 or more children (in the South). Estimating comparable cohort measures of age at grandparenthood, however, would require longitudinal data on mortality and transitions to grandparenthood over a long period (ideally, from birth until the cohort expires). Thus, estimating cohort measures would be possible only for historical cohorts, not contemporary ones. By definition, period measures combine data on multiple cohorts and, although a useful and necessary snapshot in the absence of better data, one must interpret findings keeping in mind the potential biases arising from the selection into grandparenthood over time, across areas, and by parity. Detailed prospective cohort analysis of the life course trajectories and transitions to parenthood and grandparenthood is a topic for future research as data become available.

Finally, it is worth mentioning that because the timing of entry into parenthood is closely linked to level of educational attainment, the observed changes in the demography of grandparenthood may be partly a by-product of the intergenerational transmission of patterns of education (Roksa and Potter 2011), with highly educated mothers more likely to have children later (Rendall et al. 2010) and children of highly educated mothers more likely to postpone the first birth (Rijken and Liefbroer 2009). Also, such changes might be the result of the educational expansion in Italy, where the percentage of those with secondary education rose from $7 \%$ among those born in the early 1920 s to $42 \%$ among those born in the 1960s (Checchi et al. 2007), with generally lower levels of education in the South. Further investigations onto other socio-economic, cultural, migratory, and institutional shifts which might explain the findings presented in this study (such as changes in female employment, attitudes related to women's social and family roles, and marital status and cohabitation to name a few) are also warranted.

Despite these limitations, our study has offered new insights on the extent to which the delay of grandparenthood is attributable to compositional fertility changes (such as postponement of first birth and reduction in family size). Current and future trends in fertility will impact on the future evolution of the demography of grandparenthood, with relevant implications for intergenerational relationships and transfers.

Acknowledgments This study use data from the survey Famiglia, soggetti sociali e condizione dell'infanzia', which is carried out periodically by the Italian National Institute of Statistics (ISTAT). This microdata are made publicly available by ISTAT for research purposes (https://www.istat.it/it/archivio/5725). Our study did not require ethics committee approval, as ISTAT produces and disseminates only information collected in full compliance with the regulations pertaining to the privacy of respondents. The opinions expressed herein are solely those of the authors and are not meant to represent the opinions or official positions of the Italian National Institute of Statistics.

Availability of Data and Material Data used in this study are made publicly available by ISTAT for research purposes (https://www.istat.it/it/archivio/5725). 


\section{Compliance with Ethical Standards}

Conflict of Interest The authors declare that they have no conflict of interest.

Disclaimer The opinions expressed herein are solely those of the authors and are not meant to represent the opinions or official positions of the Italian National Institute of Statistics.

Open Access This article is licensed under a Creative Commons Attribution 4.0 International License, which permits use, sharing, adaptation, distribution and reproduction in any medium or format, as long as you give appropriate credit to the original author(s) and the source, provide a link to the Creative Commons licence, and indicate if changes were made. The images or other third party material in this article are included in the article's Creative Commons licence, unless indicated otherwise in a credit line to the material. If material is not included in the article's Creative Commons licence and your intended use is not permitted by statutory regulation or exceeds the permitted use, you will need to obtain permission directly from the copyright holder. To view a copy of this licence, visit http://creativecommons.org/licenses/by/4.0/.

\section{References}

Aassve, A., Meroni, E., \& Pronzato, C. (2012). Grandparenting and childbearing in the extended family. European Journal of Population / Revue européenne de Démographie, 28(4), 499-518. https://doi.org/ 10.1007/s10680-012-9273-2.

Arpino, B., \& Bordone, V. (2014). Does Grandparenting pay off? The effect of child care on Grandparents' cognitive functioning. Journal of Marriage and Family, 76(2), 337-351. https://doi.org/10.1111/jomf. 12096.

Arpino, B., \& Bordone, V. (2017). Regular provision of grandchild care and participation in social activities. Review of Economics of the Household, 15(1), 135-174. https://doi.org/10.1007/s11150-016-9322-4.

Arpino, B., \& Gómez-León, M. (2019). Consequences on depression of combining grandparental childcare with other caregiving roles. Aging \& Mental Health, 24, 1-8. https://doi.org/10.1080/13607863.2019. 1584788 .

Arpino, B., \& Tavares, L. P. (2013). Fertility and values in Italy and Spain: A look at regional differences within the European context. Population Review, 52(1). https://doi.org/10.1353/prv.2013.0004.

Arpino, B., Pronzato, C. D., \& Tavares, L. P. (2014). The effect of grandparental support on mothers' labour market participation: An instrumental variable approach. European Journal of Population, 30(4), 369390. https://doi.org/10.1007/s10680-014-9319-8.

Barclay, K., Keenan, K., Grundy, E., Kolk, M., \& Myrskylä, M. (2016). Reproductive history and postreproductive mortality: A sibling comparison analysis using Swedish register data. Social Science \& Medicine, 155, 82-92. https://doi.org/10.1016/j.socscimed.2016.02.043.

Bengtson, V. L. (2001). Beyond the nuclear family: The increasing importance of multigenerational bonds. Journal of Marriage and Family, 63(1), 1-16. https://doi.org/10.1111/j.1741-3737.2001.00001.x.

Beugelsdijk, S., Van Schaik, T., \& Arts, W. (2006). Toward a unified Europe? Explaining regional differences in value patterns by economic development, cultural heritage and historical shocks. Regional Studies, 40(3), 317-327. https://doi.org/10.1080/00343400600631590.

Billari, F. C., \& Kohler, H.-P. (2000). The impact of union formation dynamics on first births in West Germany and Italy: Are there signs of convergence? MPIDR Working Papers, 8. https://doi.org/10.4054/ MPIDR-WP-2000-008.

Billari, F. C., Philipov, D., \& Baizán, P. (2001). Leaving home in Europe: The experience of cohorts born around 1960. International Journal of Population Geography, 7(5), 339-356. https://doi.org/10.1002/ ijpg. 231.

Blossfeld, H.-P., Golsch, K., \& Rohwer, G. (2007). Event history analysis with Stata. Mahwah: Lawrence Erlbaum Associates Publishers.

Bordone, V., \& Arpino, B. (2016). Do grandchildren influence how old you feel? Journal of Aging and Health, 28(6), 1055-1072. https://doi.org/10.1177/0898264315618920.

Caltabiano, M. (2016). A turning point in Italian fertility. Journal of Population Research, 33(4), 379-397. https://doi.org/10.1007/s12546-016-9169-9. 
Campisi, N., Kulu, H., Mikolai, J., Klüsener, S., \& Myrskylä, M. (2020). Spatial variation in fertility across Europe: Patterns and determinants. Population, Space and Place, 26(4), e2308. https://doi.org/10.1002/ psp. 2308 .

Chatterji, S., Byles, J., Cutler, D., Seeman, T., \& Verdes, E. (2015). Health, functioning, and disability in older adults - Present status and future implications. The Lancet, 385(9967), 563-575. https://doi.org/10.1016/ S0140-6736(14)61462-8.

Checchi, D., Fiorio, C., \& Leonardi, M. (2007). Sessanta anni di istruzione scolastica in Italia. Rivista di politica Economica, 96(4), 285-318.

Chen, F., \& Liu, G. (2012). The health implications of grandparents caring for grandchildren in China. The Journals of Gerontology Series B: Psychological Sciences and Social Sciences, 67B(1), 99-112. https:// doi.org/10.1093/geronb/gbr132.

Dalla Zuanna, G., \& Micheli, G. A. (2004). Strong family and low fertility:a paradox? Netherlands: Springer.

De Winter, T., \& Van Bavel, J. (2013). Becoming a grandparent and early retirement in Europe. European Sociological Review, 29(6), 1295-1308. https://doi.org/10.1093/esr/jct005.

Di Gessa, G., Glaser, K., Price, D., Ribe, E., \& Tinker, A. (2016). What drives National Differences in intensive grandparental childcare in Europe? The Journals of Gerontology Series B: Psychological Sciences and Social Sciences, 71(1), 141-153. https://doi.org/10.1093/geronb/gbv007.

Di Gessa, G., Glaser, K., \& Tinker, A. (2016a). The health impact of intensive and nonintensive grandchild Care in Europe: New evidence from SHARE. The Journals of Gerontology Series B: Psychological Sciences and Social Sciences, 71(5), 867-879. https://doi.org/10.1093/geronb/gbv055.

Di Gessa, G., Glaser, K., \& Tinker, A. (2016b). The impact of caring for grandchildren on the health of grandparents in Europe: A lifecourse approach. Social Science \& Medicine, 152, 166-175. https://doi.org/ 10.1016/j.socscimed.2016.01.041.

Duranton, G., Rodríguez-Pose, A., \& Sandall, R. (2009). Family types and the persistence of regional disparities in Europe. Economic Geography, 85(1), 23-47. https://doi.org/10.1111/j.1944-8287.2008. 01002.x.

Evandrou, M., \& Glaser, K. (2004). Family, work and quality of life: Changing economic and social roles through the lifecourse. Ageing and Society, 24(5), 771-791. https://doi.org/10.1017/ S0144686X04002545.

Felice, E. (2007). I divari regionali in Italia sulla base degli indicatori sociali (1871-2001). Rivista di Politica Economica, 97(2), 359-406.

Frejka, T., \& Sardon, J.-P. (2006). First birth trends in developed countries: A cohort analysis. MPIDR Working Paper, (14).

Grundy, E., \& Tomassini, C. (2005). Fertility history and health in later life: A record linkage study in England and Wales. Social Science \& Medicine, 61(1), 217-228. https://doi.org/10.1016/j.socscimed.2004.11.046.

Hagestad, G. O. (2006). Transfers between grandparents and grandchildren: The importance of taking a threegeneration perspective. Zeitschrift Fur Familienforschung, 18, 315-332.

Hagestad, G. O., \& Lang, M. E. (1986). The transition to grandparenthood: Unexplored issues. Journal of Family Issues, 7(2), 115-130. https://doi.org/10.1177/019251386007002001.

Hank, K., \& Buber, I. (2009). Grandparents caring for their grandchildren: Findings from the 2004 survey of health, ageing, and retirement in Europe. Journal of Family Issues, 30(1), 53-73. https://doi.org/10.1177/ $0192513 \times 08322627$.

Hank, K., Cavrini, G., Di Gessa, G., \& Tomassini, C. (2018). What do we know about grandparents? Insights from current quantitative data and identification of future data needs. European Journal of Ageing, 15(3), 225-235. https://doi.org/10.1007/s10433-018-0468-1.

ISTAT. (1997). La fecondità nelle regioni italiane. Analisi per coorti. Anni 1952-1993 (Vol. 35). Rome.

ISTAT. (2009). Multiscopo ISTAT - Famiglia e soggetti sociali.

ISTAT. (2017). Population and households. Retrieved from http://dati.istat.it. From ISTAT http://dati.istat.it

Jappens, M., \& Van Bavel, J. (2012). Regional family norms and child care by grandparents in Europe. Demographic Research, 27, 85-120 Retrieved from http://www.jstor.org/stable/26349918.

Kaufman, G., \& Elder, G. H. (2003). Grandparenting and age identity. Journal of Aging Studies, 17(3), 269282. https://doi.org/10.1016/S0890-4065(03)00030-6.

Keenan, K., \& Grundy, E. (2018). Fertility history and physical and mental health changes in European older adults. European Journal of Population., 35, 459-485. https://doi.org/10.1007/s10680-018-9489-x.

Kim, K. (2014). Intergenerational transmission of age at first birth in the United States: Evidence from multiple surveys. Population Research and Policy Review, 33(5), 649-671. https://doi.org/10.1007/ s11113-014-9328-7.

Leopold, T., \& Skopek, J. (2015a). The demography of grandparenthood: An international profile. Social Forces, 94(2), 801-832. https://doi.org/10.1093/sf/sov066. 
Leopold, T., \& Skopek, J. (2015b). The delay of grandparenthood: A cohort comparison in east and West Germany. Journal of Marriage and Family, 77(2), 441-460. https://doi.org/10.1111/jomf.12169.

Lesthaeghe, R. (2010). The unfolding story of the second demographic transition. Population and Development Review, 36(2), 211-251. https://doi.org/10.1111/j.1728-4457.2010.00328.x.

Lumsdaine, R. L., \& Vermeer, S. J. (2015). Retirement timing of women and the role of care responsibilities for grandchildren. Demography, 52(2), 433-454. https://doi.org/10.1007/s13524-015-0382-5.

Margolis, R. (2016). The changing demography of grandparenthood. Journal of Marriage and Family, 78(3), 610-622. https://doi.org/10.1111/jomf.12286.

Margolis, R., \& Verdery, A. M. (2019). A cohort perspective on the demography of grandparenthood: Past, present, and future changes in race and sex disparities in the United States. Demography, 56(4), 14951518. https://doi.org/10.1007/s13524-019-00795-1.

Margolis, R., \& Wright, L. (2017). Healthy grandparenthood: How long is it, and how has it changed? Demography, 54(6), 2073-2099. https://doi.org/10.1007/s13524-017-0620-0.

Miettinen, A., Rotkirch, A., Szalma, I., Donno, A., \& Tanturri, M.-L. (2015). Increasing childlessness in Europe: time trends and country differences. Retrieved from

Murphy, M. (2011). Long-term effects of the demographic transition on family and kinship networks. Population and Development Review, 37 (supplement), 55-80. https://doi.org/10.1111/j.1728-4457. 2011.00378.x.

Phillips, D. L., \& Alexander-Eitzman, B. (2016). Intersections of poverty, geography, and custodial grandparent caregiving in Appalachia. GrandFamilies: The Contemporary Journal of Research, Practice and Policy, 3(1).

Pink, S. (2018). Anticipated (grand-)parental childcare support and the decision to become a parent. European Journal of Population, 34(5), 691-720. https://doi.org/10.1007/s10680-017-9447-z.

Rendall, M., Aracil, E., Bagavos, C., Couet, C., Derose, A., Digiulio, P., et al. (2010). Increasingly heterogeneous ages at first birth by education in southern European and Anglo-American family-policy regimes: A seven-country comparison by birth cohort. Population Studies, 64(3), 209-227. https://doi. org/10.1080/00324728.2010.512392.

Rijken, A. J., \& Liefbroer, A. C. (2009). Influences of the family of origin on the timing and quantum of fertility in the Netherlands. Population Studies, 63(1), 71-85. https://doi.org/10.1080/ 00324720802621575.

Roksa, J., \& Potter, D. (2011). Parenting and academic achievement:Intergenerational transmission of educational advantage. Sociology of Education, 84(4), 299-321. https://doi.org/10.1177/ 0038040711417013.

Rosina, A. (2004). Family formation and fertility in Italy. A cohort perspective. In G. Dalla Zuanna \& G. A. Micheli (Eds.), Strong family and low fertility: A paradox? Dordrecht: Kluwer Academic Publishers.

Rosina, A., \& Fraboni, R. (2004). Is marriage losing its centrality in Italy? Demographic Research, 11(6), 149-172. https://doi.org/10.4054/DemRes.2004.11.6.

Salvini, S., \& De Rose, A. (2011). Rapporto sulla popolazione : l'Italia a 150 anni dall'Unità (Vol. 595). Bologna: Il mulino.

Santarelli, E. (2011). Economic resources and the first child in Italy: A focus on income and job stability. Demographic Research, S12(9), 311-336. https://doi.org/10.4054/DemRes.2011.25.9.

Santarelli, E., \& Cottone, F. (2009). Leaving home, family support and intergenerational ties in Italy: Some regional differences. Demographic Research, 21(1), 1-22. https://doi.org/10.4054/DemRes.2009.21.1.

Sigle, W. (2008). England and Wales: Stable fertility and pronounced social status differences. Demographic Research, S7(15), 455-502. https://doi.org/10.4054/DemRes.2008.19.15.

Skopek, J., \& Leopold, T. (2017). Who becomes a grandparent - And when? Educational differences in the chances and timing of grandparenthood. Demographic Research, 37(29), 917-928. https://doi.org/10. 4054/DemRes.2017.37.29.

Sobotka, T. (2017). Childlessness in Europe: Reconstructing long-term trends among women born in 19001972. In M. Kreyenfeld \& D. Konietzka (Eds.), Childlessness in Europe: Contexts, causes, and consequences (pp. 17-53). Cham: Springer International Publishing.

Steenhof, L., \& Liefbroer, A. C. (2008). Intergenerational transmission of age at first birth in the Netherlands for birth cohorts born between 1935 and 1984: Evidence from municipal registers. Population Studies, 62(1), 69-84. https://doi.org/10.1080/00324720701788616.

Szinovacz, M. E. (1998). Grandparents today: A demographic profile. The Gerontologist, 38(1), 37-52. https://doi.org/10.1093/geront/38.1.37.

Tanturri, M. L., \& Mencarini, L. (2004). Un ritratto delle donne senza figli. In M. Livi Bacci (Ed.), La bassa fecondità italiana tra costrizioni economiche e cambio di valori. Roma: Accademia Nazionale dei Lincei. 
Tsai, F.-J., Motamed, S., \& Rougemont, A. (2013). The protective effect of taking care of grandchildren on elders' mental health? Associations between changing patterns of intergenerational exchanges and the reduction of elders' loneliness and depression between 1993 and 2007 in Taiwan. BMC Public Health, 13, 567. https://doi.org/10.1186/1471-2458-13-567.

Viazzo, P. P. (2003). What's so special about the Mediterranean? Thirty years of research on household and family in Italy. Continuity and Change, 18(1), 111-137. https://doi.org/10.1017/S0268416003004442.

Vlachantoni, A., Evandrou, M., Falkingham, J., \& Gomez-Leon, M. (2019). Caught in the middle in mid-life: Provision of care across multiple generations. Ageing and Society, 40, 1-21. https://doi.org/10.1017/ S0144686X19000047.

Zamberletti, J., Cavrini, G., \& Tomassini, C. (2018). Grandparents providing childcare in Italy. European Journal of Ageing, 15(3), 265-275. https://doi.org/10.1007/s10433-018-0479-y.

Zanasi, F., Sieben, I., \& Uunk, W. (2019). Work history, economic resources, and women's labour market withdrawal after the birth of the first grandchild. European Journal of Ageing., 17, 109-118. https://doi. org/10.1007/s10433-019-00525-X.

Publisher's Note Springer Nature remains neutral with regard to jurisdictional claims in published maps and institutional affiliations. 